\title{
Jean Balsamo, Byzance à Paris: Chalcondyle, Vigenère, L'Angelier
}

\section{Filippo Fonio}

\section{Q OpenEdition}

1 Journals

\section{Edizione digitale}

URL: http://journals.openedition.org/studifrancesi/34572

DOI: $10.4000 /$ studifrancesi.34572

ISSN: 2421-5856

\section{Editore}

Rosenberg \& Sellier

\section{Edizione cartacea}

Data di pubblicazione: 1 novembre 2005

Paginazione: 406

ISSN: 0039-2944

\section{Notizia bibliografica digitale}

Filippo Fonio, «Jean Balsamo, Byzance à Paris: Chalcondyle, Vigenère, L'Angelier», Studi Francesi [Online], 146 (XLIX | II) | 2005, online dal 30 novembre 2015, consultato il 19 avril 2021. URL: http://

journals.openedition.org/studifrancesi/34572 ; DOI: https://doi.org/10.4000/studifrancesi.34572

Questo documento è stato generato automaticamente il 19 avril 2021.

\section{(c) (i) (9)}

Studi Francesi è distribuita con Licenza Creative Commons Attribuzione - Non commerciale - Non opere derivate 4.0 Internazionale. 


\title{
Jean Balsamo, Byzance à Paris: Chalcondyle, Vigenère, L'Angelier
}

\author{
Filippo Fonio
}

\section{NOTIZIA}

JEAN BALSAMO, Byzance à Paris: Chalcondyle, Vigenère, L'Angelier, in LIANA NISSIM, SILVIA RIVA, a cura di, Sauver Byzance de la barbarie du monde, Atti del Convegno di Gargnano del Garda, 14-17 maggio 2003, Milano, Istituto Editoriale Universitario Cisalpino, Monduzzi Editore («Quaderni di Acme», 65), 2004, pp. 197-212.

1 L'intervento di Balsamo fa parte degli Atti del terzo seminario Balmas, Letteratura e Immaginario, Lingua e Testo, organizzato dalla sezione di Francesistica del Dipartimento di Scienze del Linguaggio e Letterature straniere comparate, Facoltà di Lettere e Filosofia, Università degli Studi di Milano, incentrato appunto sull'immaginario culturale di Bisanzio. Partendo dalle Recherches de la France di Pasquier, che individuano Bisanzio come la «nouvelle Rome», lo studioso si concentra su alcuni dei momenti in cui le lettere francesi del Cinquecento si sono interessate a Bisanzio/Costantinopoli. Tale interesse appare per la verità discontinuo, relativamente tardivo se paragonato ad altri contesti culturali, come quello italiano, nonché spesso subordinato all'attenzione per la romanità, tanto sul piano di paradigma storico quanto su quello antiquario. Nel 1577 è data alle stampe la traduzione di Blaise de Vigenère delle Historiarum demonstrationes di Nicolas Chalcondyle, storico bizantino del secolo precedente, scarsamente considerato dagli storiografi francesi contemporanei di Vigenère, primo fra tutti Jean Bodin. Condotta sulla versione latina curata da Clauser (Bâle, 1556), la traduzione francese di Vigenère viene ristampata nel 1584 da Abel L'Angelier. Altre edizioni dell'opera seguiranno, nella forma di un pregiato in folio illustrato contenente altri scritti di Vigenère, nel 1612, 1616, 1619 e ancora l'anno seguente. Se il tentativo di Vigenère di adattare i modelli allo stile del francese ha valore di per sé, non può non essere tenuta in considerazione la componente celebrativa della traduzione in favore della famiglia Gonzaga, alleata dei condottieri francesi che portarono alla presa di Costantinopoli nel 
corso della quarta crociata. La celebrazione dell'impero turco, presente nella storia di Chalcondyle e nella versione latina di Clauser, viene pertanto subordinata da Vigenère all'intento encomiastico nei confronti dei Gonzaga-Nevers, mediante la teoria dell'avvicendarsi degli imperi, in base alla quale la «nuova Bisanzio» sarebbe da intendersi come la restaurazione di un ordine latino-cristiano, e non di un impero greco scismatico. 